\title{
KULTURNI TURIZAM KAO FAKTOR RAZVOJA TURIZMA U PODRUČJU PALESTINE
}

\section{Dalibor Redžić}

Član Alumni asocijacije, Univerzitet Singidunum, Beograd, Srbija
Correspondence: Dalibor Redžić

e-mail: dalibordredzic@hotmail.com

\section{Rezime:}

Kulturni turizam je danas identifikovan kao jedno od najvažnijih turističkih tržišta. Zahvaljujući svom geografskom položaju i dugoj istoriji, područje Palestine poseduje izuzetan potencijal kulturnog nasleđa. Turizam je direktni pokretač razvoja ekonomija većine zemalja na Bliskom Istoku, a najveći deo putovanja u ovaj region se isključivo realizuje obilaskom područja kulturnoistorijskog nasleđa. Države poput Izraela, Libana i Jordana ulažu konstantne napore u očuvanju i promociji svoje kulturne baštine sa ciljem privlačenja što većeg broja međunarodnih turista. Rad ima za cilj da analizira postojeće politike razvoja kulturnog turizma u području Palestine i ukaže na značaj koji ovaj oblik turizma ima, s posebnim osvrtom na pojas Gaze i Zapadnu Obalu. U skladu sa postojećim planovima razvoja kulturnog turizma u radu su predložena i potencijalna rešenja koja obuhvataju specifične zahteve, potrebe i perspektive za razvoj u navedena dva područja geografskog okvira Palestine. Ovo je posebno značajno zbog uspostavljanja balansa između sveobuhvatnog regionalnog razvoja kulturnog turizma s jedne i učestalih bezbednosnih problema u navedenom području s druge strane. Predložena moguća rešenja predstavljala bi osnovu za dalje povećanje ekonomskog razvoja turizma u području Palestine.

Ključne reči:

kultura, turizam, područje Palestine

UVOD

Turizam u području Bliskog istoka, zbog čestih pojava bezbednosnih problema beleži primetne oscilacije po pitanju razvoja međunarodnog turizma. U ovom radu posebna pažnja je usmerena na područje Palestine kao mestom susreta i preplitanja različitih kultura. Palestina zauzima geografski položaj između tri kontinenta Evrope, Azije i Afrike. Ovo područje se oduvek smatralo kolevkom svetske civilizacije, domom za tri glavne svetske religije: Hrišćanstvo, Judaizam i Islam. Područje Palestine zauzima oko $6000 \mathrm{~km}^{2}$, obuhvata pojas Gaze i Zapadnu Obalu, a prema sporazumu iz Osla 1994. godine njima upravlja Palestinski nacionalni organ (Jafar and Badaruddin, 2011). Od 1994. godine učinjeno je nekoliko značajnih koraka u promociji turizma. Kao primer izdvaja se ekonomsko-trgovinski sporazum sa Izraelom, potpisan u Kairu 4. maja 1994. Sledeći korak bilo je osnivanje Ministarstva turizma i antikviteta, koje je preuzelo odgovornost 
za unapređenje i promociju turizma u pojasu Gaze i Zapadnoj Obali. Turizam u području Bliskog istoka, a posebno u politički nestabilnim područjima karakteriše česta pojava bezbednosnih problema. Turizam u tom smislu može imati značajan uticaj na zbližavanje među kulturama, a korišćenje i valorizacija kulturnih resursa u svrhe razvoja turizma svakako može doprineti većem i boljem razumevanju među kulturama i religijama. Rad ima za cilj da ukaže na značaj koji bi kulturni turizam mogao da ima u području Gaze i Zapadne Obale u cilju njegovog razumevanja i razvoja kao pasoša mira. U skladu sa postojećim planovima razvoja kulturnog turizma ovog područja u radu su predložena i potencijalna rešenja koja obuhvataju specifične zahteve, potrebe i perspektive za razvoj u navedena dva područja geografskog okvira Palestine.

\section{ZNAČAJ KULTURNOG TURIZMA I OČUVANJE KULTURNOG I ISTORIJSKOG NASLEĐA}

Razvoj kulturnog turizma, zasnovan na razumevanju i miru, pronalaženju veze i zajedničkih imenitelja može imati ključnu ulogu u područjima zahvaćenim nemirima i političkom nestabilnošću. To vodi ka stvaranju povoljnih uslova za ekonomski i društveni razvoj. U 2017. godini ukupan doprinos turizma zaposlenosti u svetu, uključujući i indirektno podržane poslove od strane industrije iznosio je 9,9 procenata $(313,221,000)$. Ukupan doprinos turizma svetskom bruto domaćem proizvodu (GDP) u 2017. godini iznosio je 8,272.3 milijardi dolara (10,4 procenta) svetskog bruto domaćeg proizvoda (WTC, 2018). Danas kulturni turizam predstavlja jedan od značajnih oblika turizma na međunarodnom turističkom tržištu.

Kulturni turizam može biti definisan kao proces komodifikacije, odnosno pretvaranja kulturnih dobara u materijalnu/monetarnu vrednost, nostalgija za kulturnim nasleđem i prošlošću, psihološko iskustvo, radoznalost i proces učenja, savremeni oblik hodočašća, industriju koja predstavlja kulturne vrednosti, kao specifičan način kulturne potrošnje (prilagođeno na osnovu: Mousavi et al., 2017). Takođe, navedeni oblik turizma možemo shvatiti kao putovanje sa ciljem da se „doživi“ kulturno okruženje uključujući pejzaže, izvođačke i vizuelne umetnosti, način života lokalnog stanovništva, tradicije, vrednosti, događaje i druge načine kreativnosti poput procesa inter-kulturne razmene (Boukas and Lambert, 2013). Shodno tome, cilj kulturnog turizma jeste privlačenje turista čija su interesovanja usmerena ka sticanju znanja o kulturi drugih naroda, njihovoj istoriji i tradiciji, običajima, načinu života, navikama i načinu razmišljanja. Ovaj oblik turizma je u skladu sa savremenim kretanjima na turističkom tržištu, što ukazuje na njegovu dalju ekspanziju unutar turističkog sektora.

Značaj kulturnog turizma istaknut je u sledećem (Muhanna, 2006):

- Pomaže u očuvanju kulturnog nasleđa;

- Ima pozitivan ekonomski i socijalni uticaj (na lokalno stanovništvo i turiste);

- Uspostavlja i jača identitet, neguje harmoniju i razumevanje između ljudi.

Kulturni turizam doprinosi očuvanju kulture i istorijskog nasleđa. To se pre svega odnosi na obezbeđenje sredstava za očuvanje običaja i održavanje tradicija, finansiranje zaštite spomenika kulture i povećanje svesti turista o očuvanju kulturnog nasleđa. Materijalno nasleđe se može smatrati materijalnom investicijom, simbolom kulturnog izražavanja, tradicijom živog društva ili onih društava koja su nekada živela na istom području. Nematerijalno nasleđe je glavni pokretač kulturne raznolikosti. Kroz usmenu tradiciju i jezik, scensku umetnost, društvenu praksu, rituale i praznike, izražavaju se kreativnost, znanje, veštine i duh ljudi koji ga ostvaruju. Negovanjem i prenošenjem ove „žive kulturne baštine“, čuva se istorija, kultura i tradicija, koja izaziva osećaj identiteta i kontinuiteta jednog naroda. Shodno tome, materijalno i nematerijalno nasleđe predstavlja ključnu tačku za svakog ko želi da stekne bolje razumevanje društva.

Danas postoji nekoliko trendova koji utiču na tržište kulturnog turizma (Schanzel and Yeoman, 2015):

- Obrazovanje, kao najznačajniji faktor koji utiče na kulturu;

- Globalizacija, kao savremeni trend koji pospešuje kulturni turizam;

- Osobe ženskog pola danas imaju veće učešće u kulturološkim aktivnostima od muškaraca. One kontrolišu više prihoda i nalaze se na liderskim pozicijama. 


\section{UTICAJ KULTURNOG TURIZMA NA EKONOMSKI I SOCIJALNI RAZVOJ}

Kulturni turizam ima vitalnu ulogu u razvoju ekonomije i socijalnih uslova lokalnih zajednica, a takođe pruža i nove mogućnosti za ekonomski i socijalni razvoj. Zbog svojih specifičnosti ovaj vid turizma pruža alternativne mogućnosti za razvoj mnogih regiona i oblasti (Triarchi and Karamanis, 2017). Pojedini autori su izneli svoja mišljenja koja se odnose na ekonomski i socijalni razvoj kulturnog turizma.

Costa (1995) smatra da kulturni turizam predstavlja zadatak za lokalne zajednice u cilju usmeravanja maksimalno održive upotrebe turističkog potencijala kako bi se na osnovu zajedničkih aktivnosti postigli ekonomski i društveni ciljevi zajednice u celini, što vodi ka razvoju turizma. Fredine and Faulkner (2000) vide kulturni turizam kao ekonomsku aktivnost koja stvara nove mogućnosti za zaposlenje lokalnog stanovništva koje će turistima i posetiocima pružiti priliku da učestvuju i cene lokalnu kulturu. Bakri (2014) smatra da kulturni turizam stvara nova radna mesta i povećava prihode lokalnim zajednicama i regionima u kojima je mnogo komplikovanije stvoriti radna mesta u drugim sektorima.

Karakteristike kulturnog nasleđa imaju značajnu ulogu u stvaranju pozitivne slike o određenoj zemlji. Kulturno nasleđe predstavlja jedan od ključnih elemenata u stvaranju pozitivne slike o zemlji u međunarodnim okvirima i ima bitnu ulogu u očuvanju nacionalnog ponosa jednog naroda. Turisti se danas u mnogim zemljama suočavaju sa brojnim problemima, uglavnom nastalih kao posledica nesporazuma sa lokalnim stanovništvom. Kulturni turizam može olakšati razumevanje, kulturni dijalog i harmoniju između ljudi. Takođe, poznavanje kulture drugih naroda može stimulisati razumevanje i pospešiti želju za saradnjom. Poput pozitivnih uticaja, razvoj turizma može i negativno uticati na kulturu stanovništva na turističkoj destinaciji. Negativni efekti razvoja turizma su (prilagođeno na osnovu Shahzalal, 2016): adaptacija i prilagođavanje lokalnog stanovništva kulturi turista, pozajmljivanje veštačkih elemenata i dodavanje istih tradicionalnoj muzici, kulturnim događajima i aktivnostima, kulturna komodifikacija koja se ispoljava transformacijom kulturnih vrednosti i tradicije za novac.

\section{KULTURNI TURIZAM U PODRUČJU PALESTINE}

Nakon osnivanja Palestinskog nacionalnog organa, kulturni turizam u području Palestine je prošao kroz važne transformacije u cilju poboljšanja kvaliteta i unapređenja proizvoda. Od 1994. godine otpočeo je aktivan razvoj programa u skladu sa ciljevima razvoja kulturnog turizma, a u cilju obuhvatanja svih socio-kulturnih aspekata lokalnih zajednica. Međutim, uočeni su i problemi manifestovani u nedostatku adekvatne infrastrukture, odsustva planiranja, nedostatku politike za razvoj turizma, ekonomije, kulture, zaštite životne sredine, obrazovanja i socijalne politike, nedostatku kvalifikovanih kadrova u turizmu i promotivnih aktivnosti.

U 2016. godini, ostvareni prihodi od turizma u području Palestine su iznosili 305 miliona dolara, sa učešćem od 2,5 procenata u bruto domaćem proizvodu (PIPA, 2018). U odnosu na ostale privredne sektore, turizam ima najveće učešće u rastu bruto domaćeg proizvoda, i na osnovu toga predstavlja ključni osnov za budući ekonomski razvoj navedenog područja (Jafar and Badaruddin, 2011). To zahteva primenu jasno definisanog plana koji ima viziju i perspektivu. Potpuna realizacija plana zahteva aktivnu uključenost svih zainteresovanih strana u njegovoj implementaciji. Neophodno je proceniti turističku infrastrukturu i njene karakteristike, potrebne su dodatne regulative za javni i privatni sektor i poboljšanje marketinških aktivnosti u cilju stvaranja jasnije slike o području Palestine na međunarodnom turističkom tržištu. Primarni cilj je da se podstaknu strane investicije u cilju povećanja broja hotelskih objekata od sadašnjih 142 na planiranih 300, takođe potrebna je reorganizacija unutrašnjeg transporta, turističkih agencija i drugih privrednih subjekata koji su direktno ili indirektno povezani sa turističkom industrijom (PIPA, 2018). Potrebno je izdvojiti dodatna finansijska sredstva za obnovu mesta od izuzetnog kulturno-istorijskog značaja koja predstavljaju ključni potencijal za razvoj kulturnog turizma. 
Tabela 1. Ukupan broj hotelskih kapaciteta u području palestine

\begin{tabular}{lccc}
\hline \multicolumn{1}{c}{ Oblast } & Ukupan broj hotela & Ukupan broj soba & Ukupan broj kreveta \\
\hline Severna oblast Zapadne Obale & 29 & 527 & 1439 \\
\hline Centralna oblast Zapadne Obale & 34 & 1621 & 3328 \\
\hline Južna oblast Zapadne Obale & 47 & 3715 & 8108 \\
\hline Istočni Jerusalim & 20 & 1480 & 3242 \\
\hline Pojas Gaze & 12 & 536 & 985 \\
\hline Područje Palestine & 142 & 7879 & 17,102 \\
\hline
\end{tabular}

Izvor: The Palestinian Central Bureau of Statistics (2017)

U Tabeli 1 je prikazan ukupan broj smeštajnih kapaciteta koji su trenutno dostupni u području Palestine. $\mathrm{Na}$ osnovu prikazane tabele primetno je da je u centralnoj i južnoj oblasti Zapadne obale uključujući u statističkoj analizi i grad Jerusalim koncentrisan najveći broj hotela (101), imajući u vidu da ove oblasti prednjače po broju dolazaka međunarodnih turista.

Imajući u vidu da oblast Zapadne Obale i pojas Gaze imaju izuzetan potencijal za razvoj kulturnog turizma, nedovoljan broj hotelskih objekata stvara dodatne probleme za promociju i razvoj ovog vida turizma. S druge strane, turistički sektor u području Palestine karakteriše visok procenat nekvalifikovane radne snage (Al-Rimmawi and Butcher, 2015).

Grafikon 1. Ukupan broj turista koji su posetili područje palestite u periodu od 2009. do 2017.

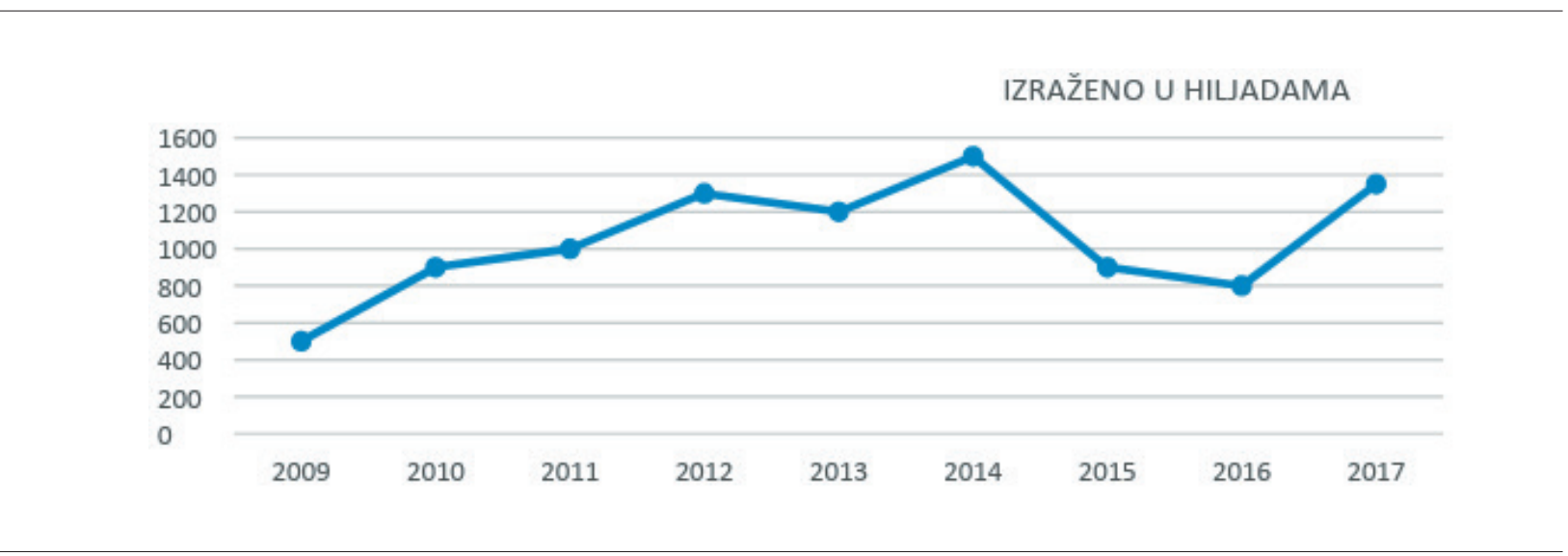

Izvor: The Palestinian Central Bureau of Statistics (2017)

Područje Palestine predstavlja jedno od potencijalno veoma značajnih turističkih tržišta u regionu Bliskog Istoka. Na osnovu grafikona 1 možemo primetiti da je u periodu od 2012. do 2014. godine navedeno područje posetio najveći broj turista. Takođe, u 2017. godini je zabeležen značajan porast broja poseta $(1,350.000)$, što je u odnosu na 2016. godinu više za 30 procenata. Gradove poput Istočnog Jerusalima i Vitlejema karakteriše kombinacija glavnih elemenata turizma ovog područja. Istraživanje sprovedeno od strane izraelskog ministarstva turizma je pokazalo da od ukupnog broja turista koji putuju u područje Palestine 91 procenat poseti Istočni Jerusalim i Vitlejem, od čega 85 procenata želi da koristi hotelski smeštaj. U navedenim gradovima je koncentrisan veliki broj sakralnih objekata i turisti iz tog razloga ostaju po više dana. 
Grafikon 2. Geografska lokacija hotela i stopa zauzetosti kapaciteta u području palestine u 2017. godini

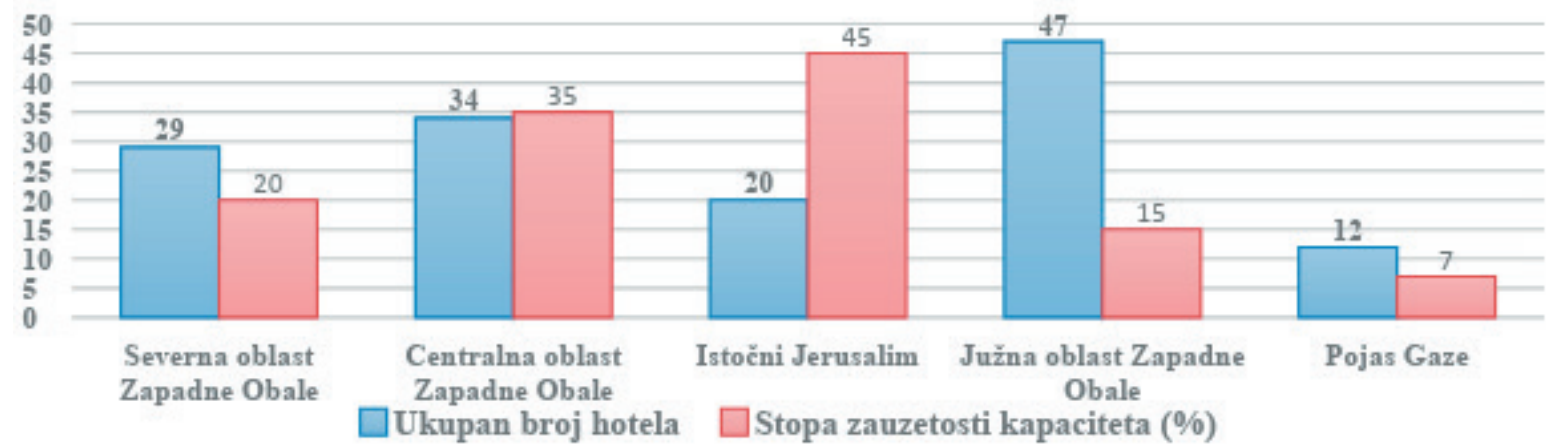

Izvor: The state of Palestine national export strategy, Tourism sector export strategy (2018)

Na osnovu grafikona 2 najposećenija oblast koja obuhvata istočni deo Jerusalima ima najveću stopu zauzetosti kapaciteta (45\%), ali ne poseduje dovoljan broj objekata za smeštaj turista (20). Shodno tome, potrebne su dodatne investicije za obnovu postojećih i izgradnju novih kapaciteta (Al-Rimmawi and Butcher, 2015).

Turizam je oduvek imao vitalnu ulogu u razvoju ekonomije ovog područja (Jafar and Raddad, 2016). Ovaj sektor nikada nije prestao da funkcioniše, čak ni u vreme ekonomskih recesija izazvanih brojnim bezbednosnim problemima koji karakterišu ovo područje. Turizam podstiče direktnu zaposlenost u okviru svog sektora $\mathrm{i}$ indirektno utiče na zaposlenost koja je u zavisnosti od njegove integracije sa drugim privrednim sektorima. Kao pouzdan generator prihoda, danas turizam učestvuje sa 4 procenata u ukupnom nacionalnom dohotku Palestine (Tabash, 2017). U pogledu značaja koji turizam ima u ekonomiji Palestinskog područja, možemo reći da kultura predstavlja važan elemenat za budući razvoj turizma.

Tabela 2. Najznačjnije turističke atraktivnosti palestinskog područja

\begin{tabular}{|c|c|c|c|c|c|}
\hline Grad & $\begin{array}{l}\text { Arheološki } \\
\text { lokaliteti }\end{array}$ & $\begin{array}{c}\text { Istorijske } \\
\text { znamenitosti }\end{array}$ & $\begin{array}{c}\text { Sakralni } \\
\text { objekti }\end{array}$ & $\begin{array}{c}\text { Muzeji i } \\
\text { kulturni centri }\end{array}$ & $\begin{array}{l}\text { Nacionalni } \\
\text { parkovi }\end{array}$ \\
\hline Jerusalim & $\begin{array}{l}\text { - Crkva svih nacija } \\
\text { i Getsimanski vrt } \\
\text { - Stari Jerusalim } \\
\text { - Terra Santa }\end{array}$ & $\begin{array}{l}\text { - Zlatna kapija } \\
\text { - Herodova } \\
\text { kapija } \\
\text { - Jaffa kapija }\end{array}$ & $\begin{array}{l}\text { - Al Aksa } \\
\text { džamija } \\
\text { - Crkva Svetog } \\
\text { Groba }\end{array}$ & $\begin{array}{l}\text { - Al Mamal } \\
\text { Fondacija } \\
\text { - Al Ruvah Teatar } \\
\text { - Dal Al Tifel } \\
\text { Organlzacija }\end{array}$ & $\begin{array}{l}\text { Mount Scopes } \\
\text { Slopes Nacion- } \\
\text { alni park }\end{array}$ \\
\hline Vitlejem & $\begin{array}{l}\text { - Herodion } \\
\text { - Solomonov bazen }\end{array}$ & $\begin{array}{l}\text { - Zidovi kralja } \\
\text { Davida } \\
\text { - Manger Skver }\end{array}$ & $\begin{array}{l}\text { - Crkva Rođenja } \\
\text { - Crkva sv. } \\
\text { Jovana }\end{array}$ & $\begin{array}{l}\text { - Al Bad Muzej } \\
\text { - Al Harah Teatar }\end{array}$ & $\begin{array}{l}\text { - Zlatna kapija } \\
\text { Nacionalni park }\end{array}$ \\
\hline Hebron & $\begin{array}{l}\text { - Al Arroub Rimski } \\
\text { bazen } \\
\text { - Tel Rumeida }\end{array}$ & $\begin{array}{l}\text { - Halhul } \\
\text { - Stara pijaca }\end{array}$ & $\begin{array}{l}\text { - Al Ibrahimi } \\
\text { džamija } \\
\text { - Ruska crkva }\end{array}$ & $\begin{array}{l}\text { - Hebron kulturni } \\
\text { forum } \\
\text { - Palestinski dečji } \\
\text { umetnički centar }\end{array}$ & $\begin{array}{l}\text { - Masafer Yatta } \\
\text { Nacionalni Park }\end{array}$ \\
\hline
\end{tabular}

Izvor : Visit Palestine (2018).

\section{POTENCIJALNA REŠENJA ZA RAZVOJ KULTURNOG TURIZMA U PODRUČJU PALESTINE}

Glavni cilj za unapređenje i razvoj kulturnog turizma u području Palestine jeste osiguranje održivog kulturnog, prostornog, socijalnog i ekonomskog razvoja koji se zasniva na održavanju, očuvanju i poboljšanju kulturnog nasleđa kroz povećanje ponude i tražnje, prodaje proizvoda i usluga, raznovrsnosti i kvaliteta. Za uspešnu realizaciju postavljenih ciljeva sledeća rešenja zaslužuju posebnu pažnju. 
Glavni principi održivog kulturnog turizma su očuvanje kulturnog nasleđa, vrednosti i tradicije, osiguranje blagostanja i poštovanje identiteta, kulture i načina života zajednice i odgovorno putovanje (Niedziolka, 2012). Turistički sektor u području Palestine treba uspeti da na održiv način osigura prezentaciju vrednosti kulturnog nasleđa za sadašnje i buduće generacije. Da bi se osigurao održivi razvoj u oblasti kulture, potrebno je obratiti posebnu pažnju na pitanja poput strategija i resursa kako bi se učvrstile veze između ekonomskog i kulturnog razvoja kroz turizam. Mestima kulturnog nasleđa potrebna je konzervacija i obnova u cilju razvoja ovog oblika turizma zarad zadovoljavanja želja i potreba turista i obezbeđenja održivih mogućnosti za lokalno stanovništvo. Društvo u celini može imati korist od aktivnosti koje su usmerene na obnovu mesta kulturnog nasleđa. Lokalne zajednice mogu biti uključene u stvaranje i raspodeli prihoda od turizma. To bi doprinelo poboljšanju socijalnog okruženja i kvaliteta života kao i stvaranju boljih mogućnosti za rekreaciju lokalnog stanovništva, što bi svakako uticalo na podizanje motivacione moći za kulturnim razvojem ovog područja.

\section{Ekonomski razvoj}

Razvoj turizma, u ovom slučaj kulturnog turizma, direktno utiče na povećanje proizvodnje i potrošnje lokalnih proizvoda i doprinosi povećanju budžetskih prihoda. Takođe, regionalni razvoj postaje efektivniji i uravnoteženiji, dolazi do poboljšanja celokupne infrastrukture, opšteg životnog okruženja i kvaliteta života lokalne zajednice. To vodi ka rastu bruto domaćeg proizvoda, povećanju budžetskih prihoda, otvaranju novih radnih mesta i povećanju plata zaposlenih.

\section{Zaštita životne sredine, obrazovanje i ulaganje u ljudski kapital}

Održivost kulturnog turizma se ogleda u očuvanju resursa prirodnog nasleđa, izbegavanju štetnih efekata kulturnog turizma, osiguranju razvoja lokalnih zajednica, ispunjenju zahteva i potreba turista i unapređenju prirodnog i kulturnog nasleđa. Da bi se ostvario razvoj kulturnog turizma potrebno je podići svest stanovništva o očuvanju kulturnog nasleđa. To se može postići promocijom vrednosti kulturnog nasleđa i edukacijom zaposlenih od strane stručnjaka, na osnovu čega će moći samostalno da upravljaju projektima koji su usmereni ka razvoju kulturnog turizma i investicija.

Turizam u području Palestine predstavlja glavni mehanizam za obezbeđenje sredstava koja su potrebna za ekonomski razvoj. Zavisnost od turizma je uslovila veliku potrebu za obrazovanjem i programima obuke. Na osnovu toga, potrebno je ispuniti određene preduslove u cilju podizanja kvaliteta usluga na viši nivo, a to su obezbeđenje fleksibilnih obrazovnih mera kao odgovor promenama na tržištu rada, poboljšanje obuke obezbeđujući stalne mogućnosti za prekvalifikaciju zaposlenih koji dolaze iz drugih sektora i veći stepen integracije pitanja vezanih za kulturno nasleđe u srednjoškolskom obrazovanju.

\section{Struktura upravljanja i razvoj infrastrukture}

Efikasno upravljanje turističkim sektorom zahteva aktivno učešće lokalnih i regionalnih vlasti u procesu planiranja, donošenja odluka i implementaciji. Potrebno je da se sve zainteresovane strane u kulturi i turizmu uključe u planiranju konzervacije i očuvanja kulturnog nasleđa kao i razvoju turističke industrije. Potrebno je uložiti dodatne napore kako bi se osigurale investicije za obnovu i razvoj infrastrukture u cilju pružanja što kvalitetnijih usluga turistima na destinaciji. Takođe, potrebno je posvetiti pažnju interesima kulturnog turizma prilikom donošenja odluka o pravljenju dugoročnih planova za razvoj infrastrukture.

Turistički sektor u području Palestine treba da sprovede obiman rad kako bi se ostvario visok stepen obostranog razumevanja između lokalnog stanovništva i turista, uzimajući u obzir dodatne koristi poput povećanja svesti o očuvanju lokalne kulture i tradicije, zaštiti životne sredine i prezentaciji flore i faune. Kulturno-istorijsko nasleđe Palestinskog područja može da pruži autentično iskustvo kulturnom turisti. Područje Palestine 
privlači turiste zbog svoje duge istorije i kulturnog diverziteta, što im pruža nezaboravno iskustvo, autentičnost i pripadnost. Shodno tome, turistički sektor treba da uloži dodatne napore kako bi zahtevi i potrebe turista bili ispunjeni na najbolji način i ne bi došlo do pojave njihovog nezadovoljstva. Radi upoređenja, većina turista koji dolaze u Jordan su bili nezadovoljni prevozom i sanitarnom opremom u hotelima, takođe su primetili da na arheološkim lokalitetima nedostaje signalizacija, informacije, brošure i mape (Jamhawi et al., 2015). Turistička industrija u području Palestine treba nastojati da se prilagodi ukusu turista poput kućne dekoracije i navika u ishrani, kako bi se podigla svest društva o unapređenju turističkih usluga. Jedan od razloga za to je sklonost turista ka „eksperimentisanju“ alternativnih načina života.

\section{ZAKLJUČAK}

Palestinskom području je potreban mir i stabilnost kako bi turističko tržište moglo nesmetano da se razvija. U poređenju sa Izraelom, navedeno područje ima znatno slabiji priliv međunarodnih turista. $\mathrm{Na}$ osnovu toga, Palestina mora razviti sopstvene strategije u skladu sa socijalnim i ekonomskim ciljevima razvoja, što bi se odrazilo na privlačenje većeg broja međunarodnih turista. Glavni nedostatak za razvoj turizma predstavlja nerazvijena infrastruktura i nedovoljan broj objekata za smeštaj turista kao i zone za turiste i centri za kulturu u urbanim oblastima. Potrebno je u saradnji sa lokalnim institucijama uložiti dodatne napore u obnovi i razvoju dotrajale infrastrukture u gradovima poput Ramalaha, Istočnog Jerusalima i Vitlejema jer ovi gradovi predstavljaju ključni potencijal za razvoj turističkog sektora u području Palestine. Pored toga, potrebni su turističko-informativni centri u manjim gradovima i arheološkim lokalitetima, pešačke staze i centri za odmor turista na Judejskim planinama.

U prvoj polovini 2018. godine 2,3 miliona turista je posetilo Izrael, od čega je 80 procenata posetilo Jerusalim, 40 procenata Vitlejem i 20 procenata Mrtvo more (CBS, 2018). Na osnovu rada, možemo zaključiti da će turizam i u budućnosti biti glavni pokretač ekonomskog razvoja navedenog područja.

\section{LITERATURA}

Al-Rimmawi, H., \& Butcher, S. (2015). Trends of tourism in Batlehem, Palestine: 1994-2015. Turizam: međunarodno znanstveni-stručni časopis, 63(3), 317-335.

Bakri, N., Jafar., M., \& Mohamad, D. (2014). Perceptions of local comnunities on the economic impacts of tourism development in Langkawi, Malaysia. 4th International Conference on Tourism Research (4ICTR), 9-11 December 2014 (pp. 1-9). Kola Kinabalu, Malaysia: SHS Web of Conferences.

Boukas, M., \& Lambert, T. (2013). Cultural tourism and sustainable development: Strategies for the sustainable development of museums in Cyprus. Trends, Impacts and Policies on Sustainable Tourism Development, International conference on tourism (ICOT), 5-8 June 2013 (pp. 83-93). Limessol, Cyprus: International Association for Tourism Policy.

CBS-Central Bureau of Statistics. (2018). Tourist arrivals in Israel. Retrieved July 27, 2018, from http://www.cbs. gov.il/reader/cw_usr_view_Folder?ID=141

Costa, J., \& Ferrone, L. (1995). Socio-cultural perspectives on tourism planning and development. International journal of contemporary hospitality management. 7(7), 27-35. doi.org/10.1108/09596119510101903

Fredline, E., \& Faulkner, B. (2000). Host community reactions: A cluster analysis. Annals of Tourism Research, 27(3), 763-784. DOI:10.1016/S0160-7383(99)00103-6

Jafar, S., \& Badaruddin, M. (2011). Factors impact on religious tourism market: The case of the Palestinian territories. International journal of business and management, 6(7), 254-260. DOI:10.5539/ijbm.v6n7p254

Jafar, S., \& Radad, S. (2016). Impact of political factor on the tourism development in Palestine: Case study of Sabastiya village. American Journal of Tourism Managment, 5(2), 29-35. DOI:10.5923/j.tourism.20160502.01

Jamhawi, M., Al-Shakarchi, N., \& Al-Hashimi, I. (2015). Assessment of tourists satisfaction in the downtown of Aman. Vicino oriente, XIX, 127-136.

Mousavi, S., Doratli, N., Mousavi, N., \& Moradiahari, F. (2016). Defining cultural tourism. International Conference on Civil, Architecture and Sustainable Development (CASD), 1-2 December 2016 (pp. 70-75). London, United Kingdom: International Institute of Chemical, Biological and Environmental Engineering. 
Morrar, R., \& Gallouj, F. (2016). The growth of the service sector in Palestine: the productivity challenge. Journal of innovation economics \& management, 1(19), 179-204. DOI:10.3917/jie.019.0179

Muhanna, E. (2006). Sustainable tourism development and environmental management for developing countries. Problems and perspectives in management, 4(2), 14-30.

Niedziolka, I. (2012). Sustainable tourism development. Regional formation and developing studies, 3(8), 157166. DOI:10.1007/3-540-25815-9_16

PIPA-Palestinian investment promotion agency. (2017). Tourism sector. Retrieved July 18, 2018, from http:// www.pipa.ps/page.php?id=1aa82by1746987Y1aa82b

Tabash, M. (2017). The role of tourism sector in economic growth: An empirical evidence from Palestine. International journal of economics and financial issues, 7(2), 103-108.

The Palestinian Central Bureau of Statistics (2017). Palestine in figures. Retrieved August 12, 2018, from http:// www.pcbs.gov.ps/Downloads/book2362.pdf

The State of Palestine National Export Strategy (2018). Tourism sector export strategy 2014-2018. Retrieved August 16, 2018, from https://www.paltrade.org/upload/multimedia/admin/2014/10/5448e8c6d8011.pdf

Triarchi, E. \& Karamanis, K. (2017). Alternative tourism development: A theoretical background. World journal of business and managment, 3(1), 35-54. DOI:10.5296/wjbm.v3i1.11198

Schanzel, H., \& Jeoman, L. (2015). Trends in family tourism. Journal of Tourism Futures, 1(2), 141-147. doi. org/10.1108/JTF-12-2014-0006

Shahzalal, M. (2016). Positive and Negative Impacts of Tourism on Culture: A Critical Review of Examples from the Contemporary Literature. Journal of Tourism, Hospitality and Sports, 20(1), 30-34.

Visit Palestine (2018). Where to go. Retrieved August 19, 2018, from http://visitpalestine.ps/where-to-go/

WTC-World Travel \& Tourism Council (2018). Travel \& tourism: Economic impact 2017 world. London: World Travel \&Tourism Council.

\title{
CULTURAL TOURISM AS A FACTOR FOR THE DEVELOPMENT OF TOURISM IN THE AREA OF PALESTINE
}

\begin{abstract}
:
Today, cultural tourism has been identified as one of the most important tourism markets. Thanks to its geographical position and long history, the area of Palestine has outstanding cultural heritage potential. Tourism is the direct driver of the development of the economies of most of the countries in the Middle East, and the largest part of the trip to this region is exclusively realized by visiting areas of cultural and historical heritage. Countries like Israel, Lebanon and Jordan are making constant efforts to preserve and promote their cultural heritage with the goal of attracting as many international tourists as possible. The aim of the paper is to analyse existing cultural tourism development policies in the area of Palestine and highlight the importance of this form of tourism, with particular reference to the Gaza Strip and the West Bank. In accordance with the existing plans for the development of cultural tourism, potential solutions are proposed that include specific requirements, needs and prospects for development in the two areas of the Palestinian geographical framework. This is particularly important because of the balance between the comprehensive regional development of cultural tourism and more frequent safety issues in the area. The proposed possible solutions would be the basis for further enhancement of the economic development of tourism in the Palestine area.
\end{abstract}

Keywords:

culture, tourism, Palestine area 